Article

\title{
Structural and Optical Characteristics of Highly UV-Blue Luminescent ZnNiO Nanoparticles Prepared by Sol-Gel Method
}

\author{
Ashraf H. Farha ${ }^{1,2} \mathbb{D}^{-}$, Abdullah F. Al Naim ${ }^{1}\left(\mathbb{D}\right.$, Javed Mazher ${ }^{1, *}{ }^{\mathbb{D}}$, Olfa Nasr $^{1}$ and \\ Mohamed Helmi Hadj Alouane ${ }^{1}$ (D) \\ 1 Department of Physics, College of Science, King Faisal University, P.O. Box: 400, Al-Ahsa 31982, \\ Saudi Arabia; afarha@kfu.edu.sa (A.H.F.); anaim2@kfu.edu.sa (A.F.A.N.); onasr@kfu.edu.sa (O.N.); \\ malouane@kfu.edu.sa (M.H.H.A.) \\ 2 Semiconductors Technology Lab, Physics Department, Faculty of Science, Ain Shams University, \\ 11566 Cairo, Egypt \\ * Correspondence: jkhan@kfu.edu.sa
}

Received: 17 December 2019; Accepted: 9 February 2020; Published: 15 February 2020

\begin{abstract}
A simple single pot sol-gel method is used to prepare $\mathrm{ZnNiO}$ nanoparticles at assorted $\mathrm{Ni}$ doping levels, 1, 3, 7 and $10 \mathrm{wt} . \%$. Structural and optical properties of nanoparticles are studied by X-ray diffraction (XRD), UV-visible diffuse reflection spectroscopy (DRS), photoluminescence (PL) measurements, scanning electron microscopy (SEM), $\mu$-Raman and X-ray photoelectron-spectroscopy (XPS). A single substitutional solid solution phase is detected in the wurtzite $\mathrm{ZnNiO}$ nanoparticles at various doping levels. XRD peak splitting and shifting is ascribed to reduced wurtzite character and presence of crystalline strain in nanoparticles at higher level of Ni doping. The Kubelka-Munk function of DRS data reveals the presence of the Burstein-Moss effect in the optical absorption of $\mathrm{ZnNiO}$ nanoparticles. Photoluminescence studies show intense UV-blue emission from $\mathrm{ZnNiO}$ nanoparticles. The UV PL also exhibits the Burstein-Moss blue shift in the ZnNiO luminescence. Raman analyses also confirms the wurtzite structure of $\mathrm{ZnNiO}$ nanoparticles; however, crystal structural defects and bond stiffness increase with Ni doping. The optical and structural studies presented in this work are pointing towards a multivalent $\mathrm{Ni}$ substitution in the nanoparticles.
\end{abstract}

Keywords: nanoparticles; sol-gel; Raman spectroscopy; UV-blue photoluminescence; ZnNiO; Kubelka-Munk function; Burstein-Moss shift; substitutional doping

\section{Introduction:}

The presence of intense luminescence in diluted magnetic semiconductor (DMS) materials has been a focus of current research interest owing to potential applications in spin-based all-optical switching, opto-spintronics and opto-spin-based computation [1-6]. Fabrication of miniaturized smart devices requires both better optoelectronic and magneto-opto-electronic efficiencies through better incorporation of dopant in nanocrystalline ZnO-based DMS systems [7-11]. The metal (TM) atom incorporation achieved from Ni doping materials in the ZnO lattice has been shown to improvise the integration of both semiconducting and magnetic properties for efficient opto-spintronics applications [12-16]. The success of TM ion doping in $\mathrm{ZnO}$ has been evident from observations of room temperature ferromagnetic (FM) ordering in $\mathrm{ZnO}$ and $\mathrm{Fe}$ atom induced bandgap tuning proved from the diffused reflectance spectroscopy of ZnFeO nanocrystals [17,18]. Moreover, novel phenomena such as poloronic magneto-resistance (MR), superior surface catalysis and super-capacitive behaviors, thermal activation of carriers, and lowering of electrical resistance are also expected in the $\mathrm{ZnNiO}$ systems [19-22]. 
It is crucial to better understand the mechanisms of incorporation of TM dopant in the host lattice because opto-electronic and magneto-electronic properties significantly depend on the synthesis methods used in preparation of TM doped ZnO nanoparticles [14,18,23]. Jlassi et al. estimated that up to $2 \% \mathrm{Ni}$ incorporation in $\mathrm{ZnO}$ prepared by spray pyrolysis technique can increase n-type carriers through O-vacancy defects [20]. Meanwhile, the free carriers are less likely generated in the sol-gel prepared $\mathrm{ZnNiO}$ due to large presence of interstitial Ni ions [24]. However, the single-pot sol-gel synthesis of $\mathrm{ZnNiO}$ nanoparticles can give different results due to simultaneous formation of cationic sub-lattice and higher photoluminescence yield can be expected due to presence of higher carrier concentrations [8].

A successful incorporation of $\mathrm{Ni}$ dopant in the nanocrystalline $\mathrm{ZnO}$ particles can also make them deployable in varisters, as battery electrode, as oxidative catalytic thin-films, super-capacitor electrodes, and so on [25-28]. Additional synthesis-dependent variables, such as the level of oxygen vacancies and higher dopant-to-dopant near-neighbor interactions, also play a significant role in the enhancement of optoelectronic and opto-spintronic properties of TM doped metal oxides [13,18,29-31]. A steep decrease in ferromagnetic behavior of $\mathrm{ZnNiO}$ was observed on increasing the Ni concentrations beyond $15 \%$ due to anti-ferromagnetic (AFM) ordering of $\mathrm{Ni}^{2+}$ ions $[17,31]$.

On a similar note, Ni doping also brings significant changes in the ZnO's crystal symmetry, local chemical environments and charge transfer mechanisms in addition to disorder and local polarizability, which are correspondingly proved from the XPS studies and the Raman scattering analysis [32,33]. Russo et al., using Raman analysis, successfully predicted presence of local structural strain in doped $\mathrm{ZnO}$ nanoparticles [34]. Similarly, oxidation states of the as-incorporated Ni atom in ZnO host affect carrier density, mobility and opto-spintronic transport processes. [35,36]. The XPS studies show that $\mathrm{Ni}^{2+}$ ion replaces $\mathrm{Zn}^{2+}$ ion in the $\mathrm{ZnO}$ cationic sub-lattice [35,37]. Ni ions' incorporation in $\mathrm{ZnO}$ nanoparticles can produce large amounts of surface defects on the nanoparticle surface resulting in the band gap tuning [33]. Fabbiyola et al. found that $\approx 5-20 \% \mathrm{Ni}$ concentration reduces $\mathrm{ZnO}$ nanoparticles' size, causing a blue shift in the energy gap observed using optical absorption derived from the Kubelka-Mulk's function of DRS data [19].

Nevertheless, the functional aspects of doped $\mathrm{ZnO}$ ternaries, especially optoelectronic and spintronic properties, depend not only on the type of synthesis method used but also on level of control over dopant substitution in host-lattice [20,35,37-39]. It is very important to check the oxidation states of the dopants incorporated in the host lattice to study the doping effects on the carrier density, mobility and other transport and optical properties [40]. Oxidation states of the dopant may vary depending on precursor composition, synthesis method, and annealing treatments [37]. Consequently, different synthesis methods may give contradictory trends of free carrier concentration. Despite many reports being available on TM atom doped $\mathrm{ZnO}$ powders, most of them fail to properly describe the effects of dopant oxidation states on optical and structural changes [41]. Here, we attempt to investigate the effects of $\mathrm{Ni}$ doping on optical and structural properties of $\mathrm{ZnNiO}$ nanoparticles.

In this report, we present a simpler method of $\mathrm{ZnNiO}$ nanoparticles synthesis using a single pot sol-gel technique. Our choice of the Ni doping range is based on an observable optical absorption shift owing to expected doping induced band structure modifications. It has been reported that significant optical and structural variations are possible in $\mathrm{ZnNiO}$ nano-powders prepared by solid-state reaction technique at $0 \%, 3 \%, 5 \%, 7 \%$ and $10 \%$ Ni doping levels [29]. Similarly, changes in optical processes in $\mathrm{ZnNiO}$ nanoparticles have also been reported for $\mathrm{Ni}$ concentration in the range of 5\%-20\% [19]. In this report, effects of dopant substitution are studied in respect to variations of structural, morphological and optical traits of $\mathrm{ZnNiO}$ nanoparticles. Any enhancement in the UV-blue emission from $\mathrm{ZnNiO}$ nanoparticles can bring a new functionality among the ZnO-based DMS materials. It would be interesting to see the effects of $\mathrm{Ni}$ doping on the wurtzite symmetry of $\mathrm{ZnNiO}$ nanoparticles or presence of any doping induced crystalline phase transformations. Moreover, the knowledge of chemical states of dopant in the host lattice would be imperative in determining the mechanism of optical processes such as Burstein-Moss shift vis-à-vis Ni doping percentage. 


\section{Experimental Details}

\subsection{Synthesis of ZnNiO Nanoparticles}

$\mathrm{ZnNiO}$ nanoparticles are prepared by single-pot sol-gel method, in which precursors like Nickel (II) nitrate hexahydrate (Sigma-Aldrich, USA, 99.5\% purity) and Zinc (II) acetate dihydrate (Sigma-Aldrich, USA, $99.8 \%$ purity) are mixed in assorted molar ratios of Ni source, 1\%, 3\%, 7\% and 10\%. Isopropyl alcohol (Sigma-Aldrich, 99.5\% purity), is used as a solvent in the bath reactor. An aqueous stock solution of zinc precursor $(0.5 \mathrm{M}), 3.5 \mathrm{~g}$ of $\mathrm{Zn}(\mathrm{II}) \cdot\left(\mathrm{CH}_{3} \mathrm{COO}\right)_{2} \cdot 2 \mathrm{H}_{2} \mathrm{O}$ powder, is first dissolved in $32 \mathrm{~mL}$ of isopropyl alcohol to initiate the hydrolysis. Then assorted weights, $0.047 \mathrm{~g}, 0.14 \mathrm{~g}, 0.33 \mathrm{~g}$ and $0.47 \mathrm{~g}$ of $\mathrm{Ni}$ precursor, $\mathrm{Ni}(\mathrm{II}) \cdot\left(\mathrm{NO}_{3}\right) \cdot 6 \mathrm{H}_{2} \mathrm{O}$, are correspondingly added to the respective $\mathrm{Zn}$ stock solutions and the mixtures are stirred for $10 \mathrm{~min}$ at room temperature. Furthermore, a suitable rate of hydrolysis is achieved by alkalization with drop-wisely addition of $1.3 \mathrm{~mL}$ of mono ethanolamine (MEA) in the solution. Throughout the $\mathrm{ZnNiO}$ synthesis, the molar ratio between isopropyl alcohol, zinc precursor and MEA is kept constant $\approx 200: 10: 1$. Afterwards, the temperature of the solution is raised to $60^{\circ} \mathrm{C}$ with continuous stirring for $2 \mathrm{~h}$ to complete the alcoholic condensation reaction, and finally a gel is obtained in the form of a fine white colored powder. The obtained gel is dried for $1 \mathrm{~h}$ at $250^{\circ} \mathrm{C}$ temperature in the oven leading to water and alcohol evaporation and subsequently calcined in air at $600{ }^{\circ} \mathrm{C}$ for $5 \mathrm{~h}$. For the assorted weight percentages of $\mathrm{Ni}, 1 \%$ to $10 \%$, different colors of $\mathrm{ZnNiO}$ powders are obtained ranging from off-white to grayish-white with respect to increasing $\mathrm{Ni}$ concentration.

\subsection{Characterization of $\mathrm{ZnNiO}$ Nanoparticles}

XRD technique is employed for structure examination of as-prepared $\mathrm{ZnNiO}$ in powder form. Powder X-ray diffractometer (Ultima-4, Rigaku, Japan) is used for XRD analysis of powdered samples. XRD measurements are obtained in a $2 \theta$ range from $20^{\circ}-80^{\circ}$ using $\mathrm{CuK}_{\alpha}(\lambda=1.5406 \AA)$ radiation source. Evaluation of microstructure and morphology of $\mathrm{ZnNiO}$ powders is performed using high-resolution scanning electron microscope (JSM-7600F, Jeol, Japan) and recorded at 100,000× and 25,000× scan magnifications. XPS technique is used to quantitatively probe chemical species and oxidation states. $\mathrm{Mg}-\mathrm{k} \alpha$ radiation (1253.6 eV) radiation source is used in XPS instrument (ESCA-II, Omicron, Germany) to record spectra at $0.05 \mathrm{eV}$ spectral resolution and at 50- $\mu \mathrm{m}$ X-ray beam spot-size. Raman Spectroscopy, a useful method for understanding lattice vibration energies, is used to study characteristic and disorder phonons present in nanoparticles. Raman spectra are recorded in confocal Raman microscope (Horiba spectrometer, Labram HR Evolution, France) at ultra-low frequency compatible scans in 50 to $800 \mathrm{~cm}^{-1}$ range using the $633 \mathrm{~nm}$ He-Ne laser excitation source. Diffusion reflectance spectroscopy is performed in spectral range of $190-1100 \mathrm{~nm}$ at $\pm 0.5 \mathrm{~nm}$ spectral accuracy using the UV-Vis spectrometer (UV1800, Shimadzu, Japan). The DRS data is collected on pelleted $\mathrm{ZnNiO}$ powders hydraulically pressed at 3.5-tons pressure. Photoluminescence (PL) measurements are also performed in the Horiba Labram PL spectrophotometer using $325 \mathrm{~nm}$ He-Cd laser excitation source.

\section{Results and Discussion}

XRD patterns of $\mathrm{ZnNiO}$ powders are shown in Figure 1a. For the sake of clarity, a vertical offset of $\mathrm{XRD}$ patterns with $\mathrm{Ni}$ doping is shown in the figure. All samples exhibit characteristic $\mathrm{ZnO}$ peaks at (100), (200) and (101) XRD reflections confirming the wurtzite structure of $\mathrm{ZnNiO}$. Additionally, the sharper and more intense nature of XRD peaks at lower Ni concentrations indicates a strong wurtzite character of $\mathrm{ZnNiO}$ nanoparticles. However, on further doping, the XRD peaks become broader and less intense, indicating decay in the wurtzite character. Nonetheless, the wurtzite structure remains a dominant phase, during compositional variation of $\mathrm{ZnNiO}$ nanoparticles, indicating a substitutional solid solution formation. Furthermore, absence of any new XRD peaks on Ni doping implies absence of secondary structural phases. Nevertheless, upon careful examination of the XRD patterns, the XRD peaks are found to be dividing into a doublet peak structure; a smaller XRD peak originates nearby each major XRD peak, reflecting a systematic development of structural changes in $\mathrm{ZnNiO}$ at higher 
Ni doping. The observation is further clarified from the XRD peak profiles of 101-reflections plotted in Figure $1 b$, which clearly show shifted and less intense peaks, reflecting a decay in the wurtzite nature of $\mathrm{ZnNiO}$. The (101)-peak becomes a clear doublet peak at $10 \% \mathrm{Ni}$ content, $\Delta 2 \theta \approx 0.61$ for $\mathrm{ZnNiO}-10$, apparently indicating reduction in wurtzite symmetry or a weaker lattice strain induced zinc-blende symmetry at higher doping. The nano phase $\mathrm{ZnNiO}$ has already been reported to grow in both wurtzite and zinc-blende metastable phases owing to similarity in their anionic coordination [17]. During the doublet development on doping, as shown in Figure $1 \mathrm{~b}$, the lower peak at $2 \theta \approx 35.5^{\circ}$ can best be attributed to a weaker zinc-Blend symmetry of $\mathrm{ZnNiO}$ nanoparticles. Herewith, we reject the possibility of any secondary oxide phase formation on doping in the light of absence of NiO's XRD peaks. It should be noted that $\mathrm{NiO}$ crystals typically adopt hexoctahedral cubic system (XRD card number: RRUFFID-R080121 [42]) and a major XRD reflection of $\mathrm{NiO}(111)$ is positioned at $2 \theta \approx 37.45$. The XRD peaks related to $\mathrm{NiO}$ cubic phase are completely absent in the $\mathrm{ZnNiO}$ XRD patterns at all doping levels implying absence of new phases. Moreover, the XRD peak shift value of $\Delta 2 \theta$ in the present studies can be best ascribed either to uniform crystalline strains present in $\mathrm{ZnNiO}$ lattice as a result of ionic radii mismatch between $\mathrm{Zn}^{2+}(0.74 \AA)$ and $\mathrm{Ni}^{2+}$ ions $(0.69 \AA)$ or to reduced symmetry defects in the crystal structure [20]. The results of the observed crystalline strain behavior in $\mathrm{ZnNiO}$ nanocrystals are also summarized in Table 1. Typically, the strain increases in $\mathrm{ZnNiO}$ nanoparticles with increasing $\mathrm{Ni}$, and its behavior agrees very well with the increase in unit cell volume.

Table 1. Summary of structural properties present in the assorted samples $\mathrm{ZnNiO}$ powders calculated by XRD data fitting. Columns from left represent Ni content (weight percentage), average crystallite size $(D)$ in nanometers $(n m)$, lattice constants $(a, c)$ and their ratio $(c / a)$, bulk strain $(\Delta d / d)$ present in $\mathrm{ZnNiO}$ nanoparticles and their unit cell volume $(\mathrm{V})$.

\begin{tabular}{ccccccc}
\hline Doping-Percent & $\mathbf{D}, \mathbf{n m}$ & $\mathbf{a}, \mathbf{\AA}$ & $\mathbf{c}, \AA$ & $\mathbf{~} / \mathbf{a}$ & Strain & $\mathbf{V}, \AA^{\mathbf{3}}$ \\
\hline $1 \%$ & $29.8 \pm 1.57$ & $3.23 \pm 0.01$ & $5.22 \pm 0.01$ & $1.600 \pm 0.01$ & 0.19 & 47.99 \\
\hline $3 \%$ & $32.2 \pm 2.41$ & $3.23 \pm 0.01$ & $5.21 \pm 0.01$ & $1.597 \pm 0.01$ & 0.01 & 47.88 \\
\hline $7 \%$ & $18.1 \pm 1.37$ & $3.28 \pm 0.02$ & $5.22 \pm 0.02$ & $1.594 \pm 0.01$ & 0.36 & 48.57 \\
\hline $10 \%$ & $14.1 \pm 0.80$ & $3.30 \pm 0.02$ & $5.24 \pm 0.04$ & $1.586 \pm 0.02$ & 0.68 & 49.54 \\
\hline
\end{tabular}

Crystallite size (D) for nanoparticles in spherical approximation can be easily calculated by measuring the (101)-peak broadening $(\beta)$ and applying Scherrer's formula, $D=K / \beta$, where constant $K$ depends on the $x$-ray source and $\theta$-position of the peak used [43]. The Scherrer's particle sizes for $\mathrm{ZnNiO}$ nanoparticles are summarized in Table 1 . $\mathrm{ZnNiO}$ particle sizes were found to systematically decrease from 32 to $14 \mathrm{~nm}$ with increasing Ni concentration, as shown in the table. The lower nanoparticle size at higher $\mathrm{Ni}$ doping also indicates higher doping related defects affecting the growth of crystallites. Lattice parameters and unit cell volume of $\mathrm{ZnNiO}$ were also found to be increasing with $\mathrm{Ni}$ content in nanoparticles, as shown in Table 1. Change in the unit cell volume can also be ascribed to the presence of uniform crystalline strain and difference in the ionic radii of the substituted $\mathrm{Ni}$ ions in comparison to $\mathrm{Zn}^{2+}$ cations [43].

Electron microscopic images of $\mathrm{ZnNiO}$ nanoparticles with different $\mathrm{Ni}$ ion concentrations are shown in Figures 2 and 3 at 25,000 $\times$ and 100,000× magnifications, respectively. In the wider area scan of Figure 2, a surface morphology consisting of nanoparticles is distinctively apparent within the rounded shaped regions of larger agglomerations. Moreover, uniformly distributed nanoparticulate morphology is also obvious among all the sol-gel prepared $\mathrm{ZnNiO}$ powders. The clusters are characteristically formed in comparable sizes and shapes, which confirms a uniform sol-gel procedure is adopted during the $\mathrm{ZnNiO}$ syntheses. SEM images for $\mathrm{ZnNiO}$ samples with higher magnification scanning are shown in Figure 3, depicting a granular morphology of nanoparticles. The grains are seemingly hexagonally faceted, indicating conservation of wurtzite structure of $\mathrm{ZnNiO}$ during Ni doping. Sharply hexagonally faceted grains can even be observed for nanoparticles at 3\% and 7\% Ni doping percentages. The 
higher magnification electron microscopy confirms the identical nature of as-formed grain sizes, along with uniform size distributions among all samples. Comparatively higher porosity and intragranular spacing is observed in the granular morphology of $\mathrm{ZnNiO}$ with lower $\mathrm{Ni}$ content-1\%. On increasing $\mathrm{Ni}$ content in remaining $\mathrm{ZnNiO}$ samples, the particle sizes remain constant at $\approx 52 \mathrm{~nm}$; nonetheless, the morphological compactness increases along with reduction in the intragranular voids.
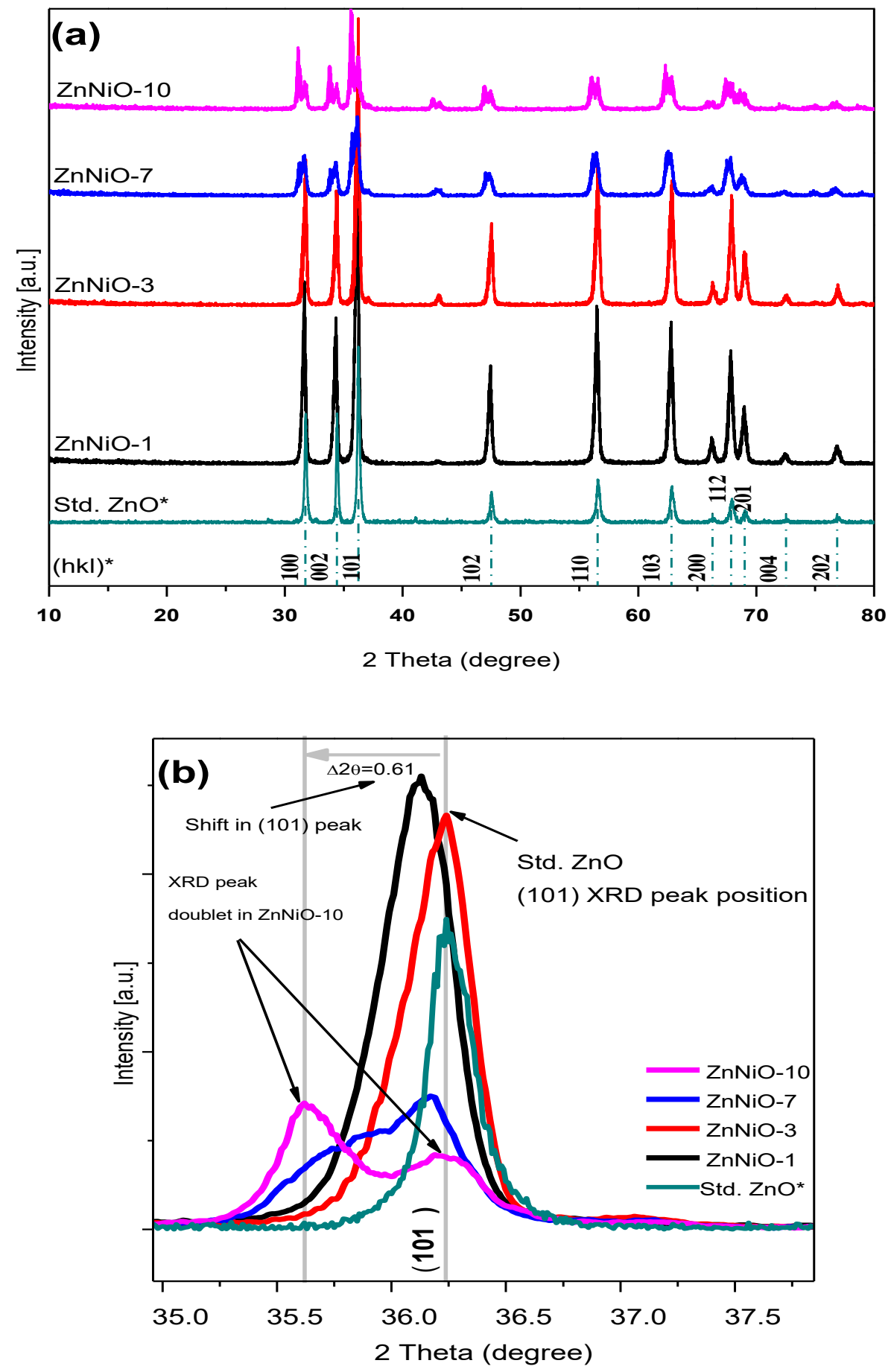

Figure 1. (a) $\mathrm{XRD}$ patterns of $\mathrm{ZnNiO}$ nanoparticles are presented in vertically aligned mode in increasing doping percentages. The Ni doping increases in samples $\mathrm{ZnNiO}-1,-3,-7$ and -10 . Asterix sign $(*)$ shows the standard $\mathrm{ZnO}$ 's XRD pattern and its (hkl) reflection positions as adopted from the XRD card, RRUFFID-R050492. (b) shows (101) -peak profiles of most intense XRD reflection in $\mathrm{ZnNiO}$ indicating a $2 \theta$ shift upon doping and a gradual development of 101-doublet peaks. 

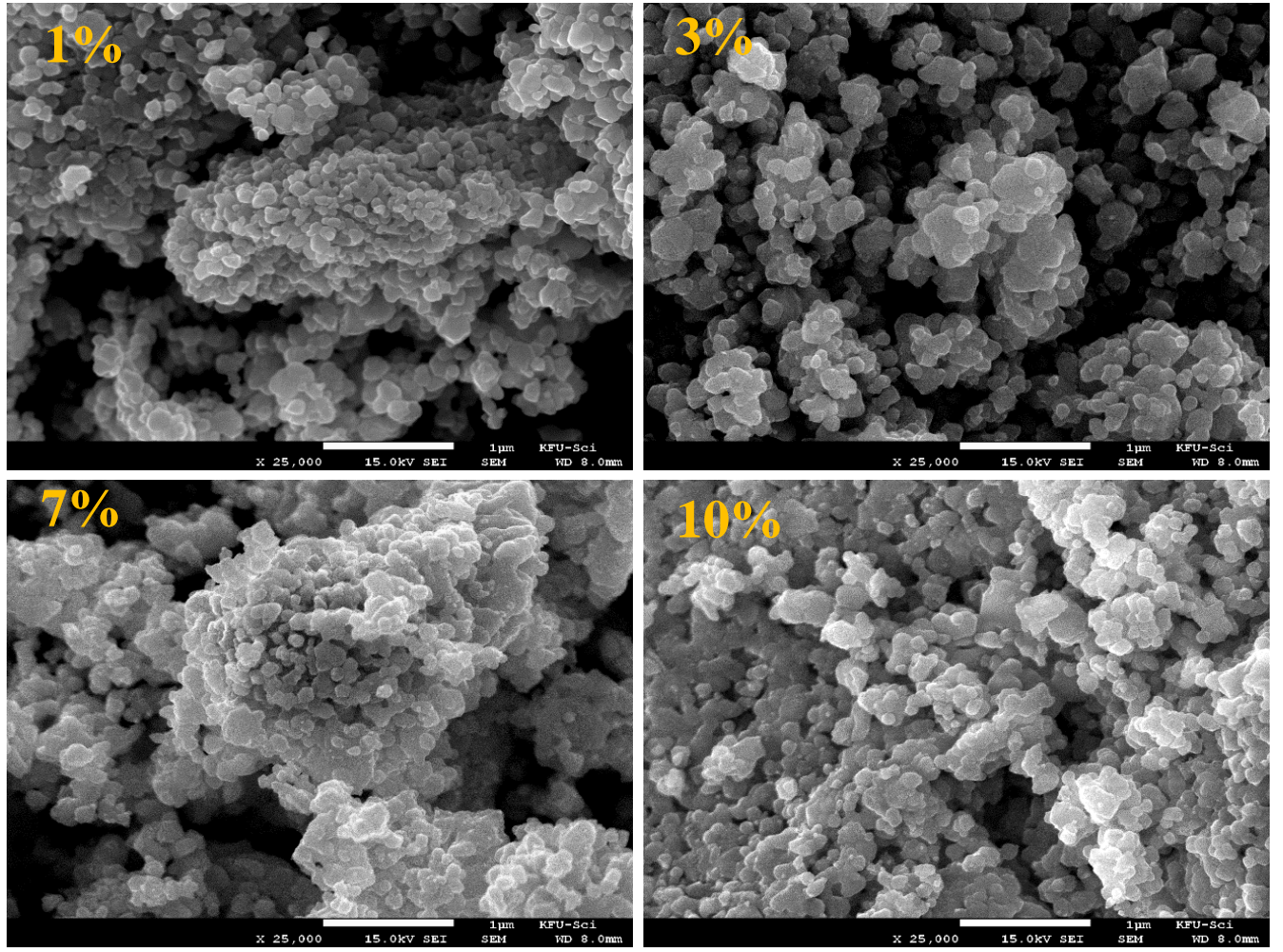

Figure 2. SEM images recorded at 25,000× magnification showing surface morphology of $\mathrm{ZnNiO}$ powders at $1 \%, 3 \%, 7 \%$ and $10 \%$ Ni doping percentages. The white colored bar-scale in the bottom of each image represents $1 \mu \mathrm{m}$.
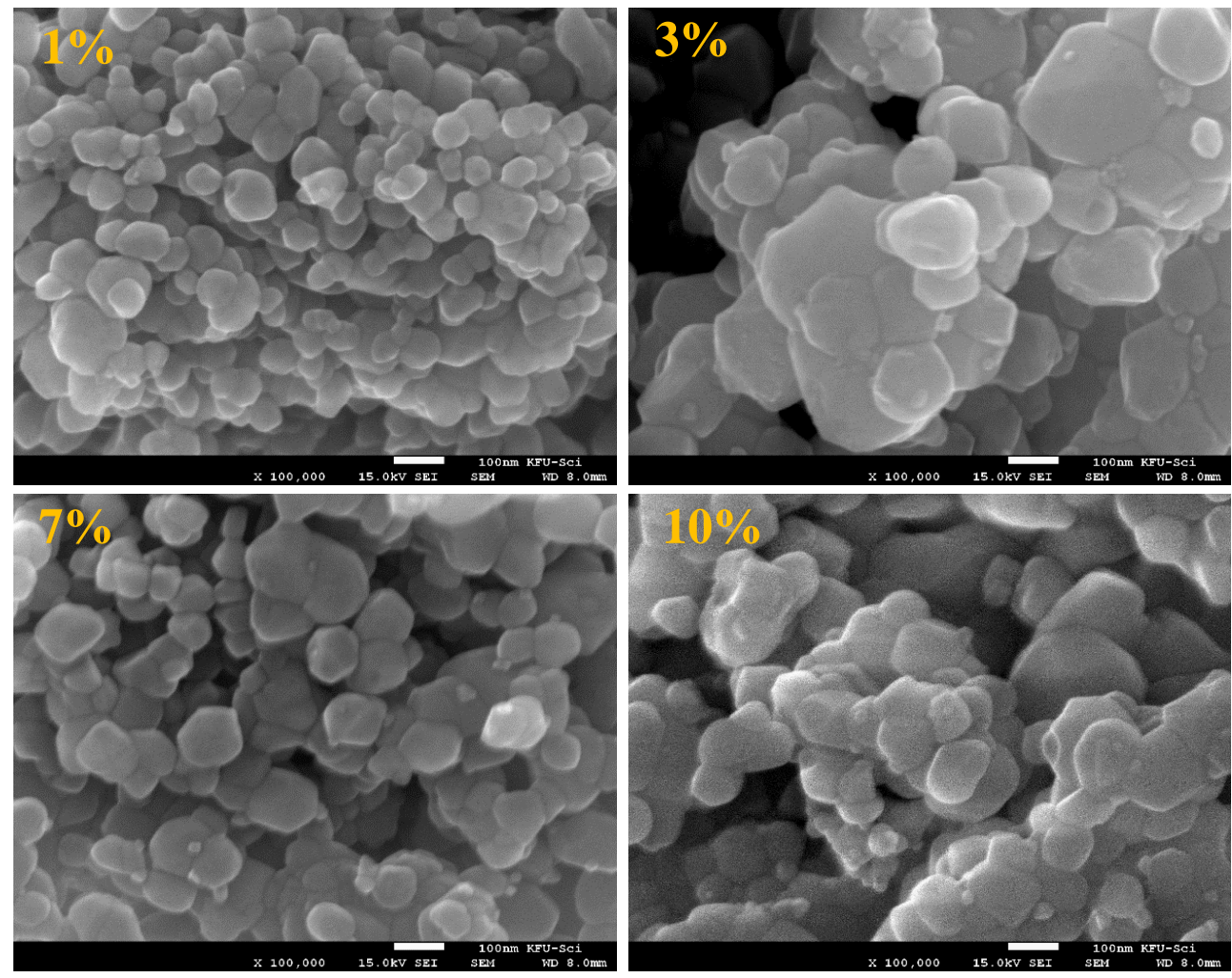

Figure 3. SEM images recorded at higher magnifications $(100,000 \times)$ showing the granular morphology of $\mathrm{ZnNiO}$ powders at $1 \%, 3 \%, 7 \%$ and $10 \%$ doping percentages. The white colored bar-scale in the bottom of each image represents $100 \mathrm{~nm}$. 
Optical absorption properties and electronic bandgap are determined using a straight-line fit on Kubelka-Munk function calculated from the diffused reflectance data. The DRS data, as shown in Figure $4 \mathrm{a}$, is plotted in the UV-Vis range for $\mathrm{ZnNiO}$ nanoparticles with vertically decreasing $\mathrm{Ni}$ concentration. The DR values recorded at different compositions of $\mathrm{ZnNiO}$ show a rapid decrease at wavelengths lower than $400 \mathrm{~nm}$. The observed reflectance feature is the most common feature among $\mathrm{ZnNiO}$ nanoparticles in UV light range due to fundamental absorption onset involving opto-electronic transition from valance band (VB) to conduction band (CB) $[1,44]$. In general, the optical reflectivity gradually decreases with $\mathrm{Ni}$ doping owing to an upsurge in the dopant related internal light scattering events [19]. Indeed, the $\mathrm{Ni}$ doping-induced increase in bond-polarizability in $\mathrm{ZnNiO}$ can also lead to higher internal light scattering and low DRS intensity $[45,46]$.
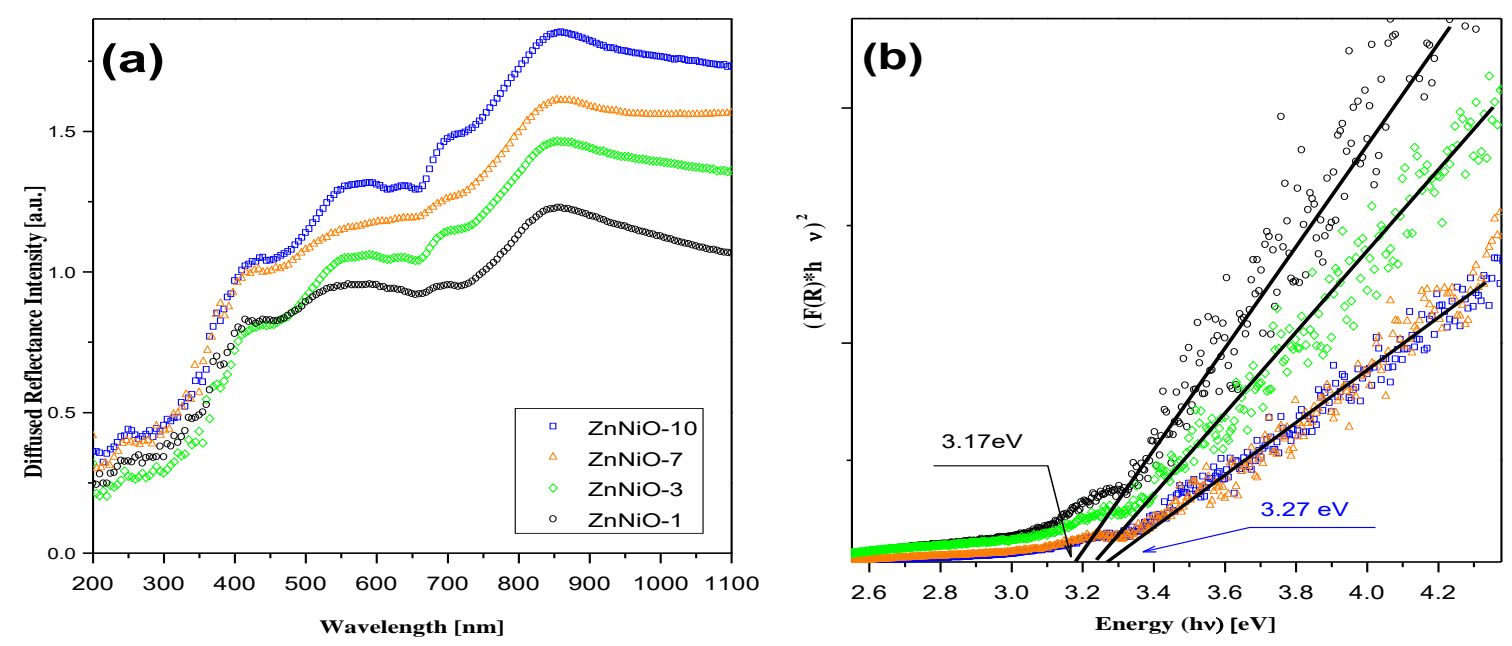

Figure 4. (a) The UV-VIS diffuse reflectance spectra for $\mathrm{ZnNiO}$ pellets are vertically stacked and plotted in the increasing Ni doping order. The doping percentages in samples, $\mathrm{ZnNiO}-1,-3,-7$ and $-10 \%$, are correspondingly plotted in black, green, red and blue colored spectral lines. (b) Kubelka-Munk fittings of the DRS are plotted in the right-hand side figure.

The Kubelka-Munk (KM) function, $F(R)=\frac{K}{S}=(1-R)^{2} / 2 R$; where $K, S$ and $R$ denote absorption, scattering and reflection coefficients, respectively, is a direct measure of the absorbance from the sample's reflectivity data. The KM function of the diffused reflection spectrum can be used in the calculation of electronic bandgap using the onset of the fundamental absorption edge [47]. The function $\left[(\mathrm{F}(\mathrm{R}) \times \mathrm{h} v]^{2}\right.$, which is a direct measure of the absorbance in the material, is plotted with respect to the photon energy $(\mathrm{hv}, \mathrm{eV})$ in Figure $4 \mathrm{~b}$. A straight-line fit is performed in a linear region of the KM function and extrapolated to baseline absorbance on the hv-axis to find the Tauc's optical bandgap, as shown in the figure. A slightly blue-shifted bandgap $(\Delta \approx 0.1 \mathrm{eV})$ is observed in $\mathrm{ZnNiO}-7$ and -10 samples in comparison to the $\mathrm{ZnNiO}-1$ and -3 samples. The bandgaps in the latter two samples with lower $\mathrm{Ni}$ concentrations are closer to the reported band gap $(\sim 3.1 \mathrm{eV})$ of standard $\mathrm{ZnO}$ [20]. A small blue shift of $\sim 0.1 \mathrm{eV}$ observed with $\mathrm{Ni}$ doping is understandably not related to quantum size confinement effects owing to non-variance of $\mathrm{ZnNiO}$ particle sizes during $\mathrm{Ni}$ doping. Fabbiyola et al., have attributed enhancements in the $\mathrm{KM}$ function in $\mathrm{ZnNiO}$ to $\mathrm{Ni}$ doping due to the formation of surface states which significantly increase the optical absorption [19]. However, we believe the increased $F(R)$ in this study is due to doping induced Burstein-Moss effect. In comparison to bivalent dopant $\left(\mathrm{Ni}^{2+}\right)$ substitution, the trivalent dopant $\left(\mathrm{Ni}^{3+}\right)$ substitution in the $\mathrm{ZnO}$ lattice replacing the divalent $\mathrm{Zn}^{2+}$ has been reported to provide an additional electron for conduction [47]. The Ni atom donating electrons to the conduction band suggestively increase the Fermi level and itinerant related absorption toward the higher energy [48]. Moreover, the KM function value in the UV-blue region is typically higher for $\mathrm{ZnNiO}$ with higher $\mathrm{Ni}$ doping, and that also indicates an increase in the overall number of optical absorption processes. Furthermore, the Ni doping-related increase in $\mathrm{ZnNiO}$ bandgap has also been 
ascribed to increase in excitonic density and excitonic mediated optical transitions resulting in highly diffused nature of DRS [49].

A possible mechanism of the Burstein-Moss-mediated optical absorption process is depicted in Figure 5 (right), illustrating itinerant related optical absorption and electron transfer from the trivalent dopant $\left(\mathrm{Ni}^{3+}\right)$ to the conduction band (CB) resulting in upshifting of the Fermi-level. Our XPS studies, which are discussed later in the manuscript, also indicate presence of trivalent $\mathrm{Ni}$ doping. Thus, the trivalent substitution of $\mathrm{Ni}$ atom in the inherently divalent cationic sub-lattice of $\mathrm{Zn}^{2+}$ ions could give electron donating character to nickel atom resulting in the higher carrier concentration effectively lifting the Fermi energy position in the band structure. While the electron transfer is proscribed in the divalent Ni substitution, as shown in Figure 5 (left).

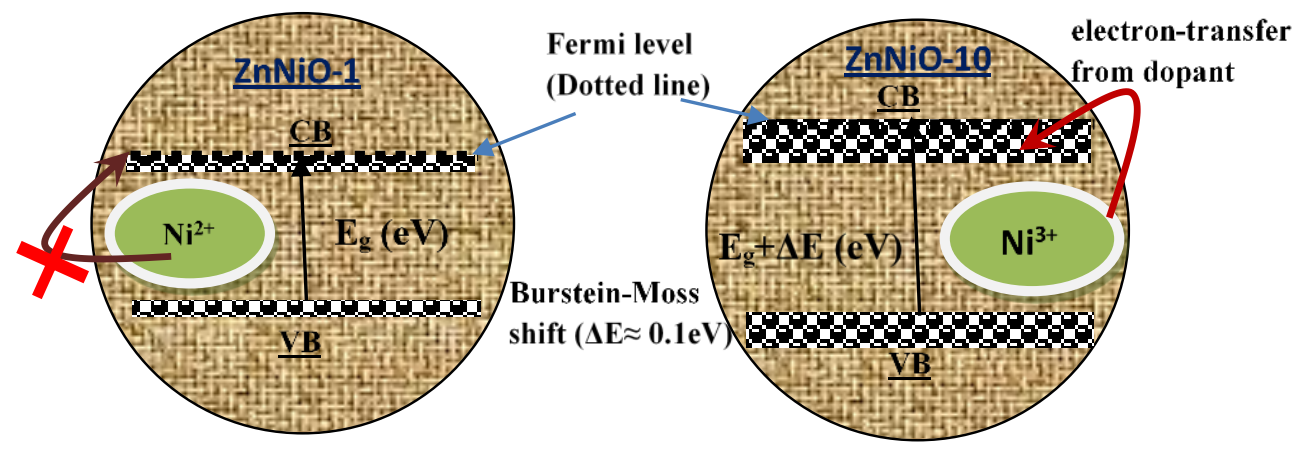

Figure 5. Optical transition processes taking place differently in $\mathrm{ZnNiO}$ nanoparticles with $1 \%$ and $10 \%$ Ni doping levels. Higher Kubelka-Munk function values $F(R)$ are expected in UV-blue region for the optical transition shown in right-side schematic of the figure.

To study the intrinsic and extrinsic defects, photoluminescence (PL) spectroscopy was carried out. Figure 6 shows room temperature PL spectra of $\mathrm{ZnNiO}$ nanoparticles excited at $325 \mathrm{~nm}$. It can be seen from the pure $\mathrm{ZnO}$ (reference sample) that the PL spectra are mainly comprised of UV emission peaks at $3.34 \mathrm{eV}(370 \mathrm{~nm})$ followed by a high-intensity broad visible band with multiple sub-peaks in the range of $2.1-2.75 \mathrm{eV}(450-590 \mathrm{~nm})$. The $\mathrm{UV}$ emission is attributed to the recombination of free excitons in the near band edge (NBE) of $\mathrm{ZnO}$, whereas the visible band is generally interpreted as the reason for the defects [8,50-53]. Meanwhile, the origins of different visible emissions are still not fully assumed and different controversial hypotheses have been offered [8,50-53]. In our case, the emission features at $2.43 \mathrm{eV}(510 \mathrm{~nm})$ and $2.21 \mathrm{eV}(560 \mathrm{~nm})$ are related to antisite oxide $(\mathrm{OZn})$ and to transmission from conduction band to vacancy, respectively.

It is shown in Figure 6a that with Ni incorporation, the UV emission intensity typically increases and is shifted to the higher energy, while the intensities of the visible peaks decreases. The results show that $\mathrm{Ni}$ doping increases the electron concentration, and that there is a concomitant decrease in the OZn and vacancy defects. On the other hand, additional broad band emissions start becoming apparent at low energy (1.8-2.2 eV) in $\mathrm{ZnNiO}$ samples. The broad band is deconvoluted for two different peaks, as shown in Figure 6b. The emission peak at $2.04 \mathrm{eV}(607 \mathrm{~nm})$ corresponds to Ni-related defects, and the peaks at $2.13 \mathrm{eV}(582 \mathrm{~nm})$ correspond to donor-acceptor pair recombination [52]. For more details, Figure $6 \mathrm{c}$ shows changes in the integrated PL intensity of the UV band ( $\mathrm{I}_{\mathrm{UV}}$ ), the wide defect-related band ( $\left.\mathrm{I}_{\mathrm{def}}\right)$ and the relative PL peak intensities ratio $\mathrm{R}\left(\mathrm{I}_{\mathrm{UV}} / \mathrm{I}_{\mathrm{def}}\right)$. From our PL observation, it is evident that Ni doping results in enhancement of luminescence arising in the UV band. Meanwhile, the wide defect-related band decreases in comparison to that of the pure $\mathrm{ZnO}$ luminescence, as observed in the same plot. Furthermore, the intensity ratio R increases with increasing Ni content and gets saturated at $7 \%$ and $10 \% \mathrm{Ni}$ concentration, showing higher enhancement of UV emission. It is interesting to note that the UV emission is also blue-shifted when the Ni concentration increases from $1 \%$ to $10 \%$ due to the Burstein-Moss effect [8]. The electron-doped $\mathrm{ZnNiO}$ with a high concentration of n-type states 
populated within the conduction band moves the Fermi level to higher energies. The filling of the conduction band by electrons will generally result in a blue shift [8].
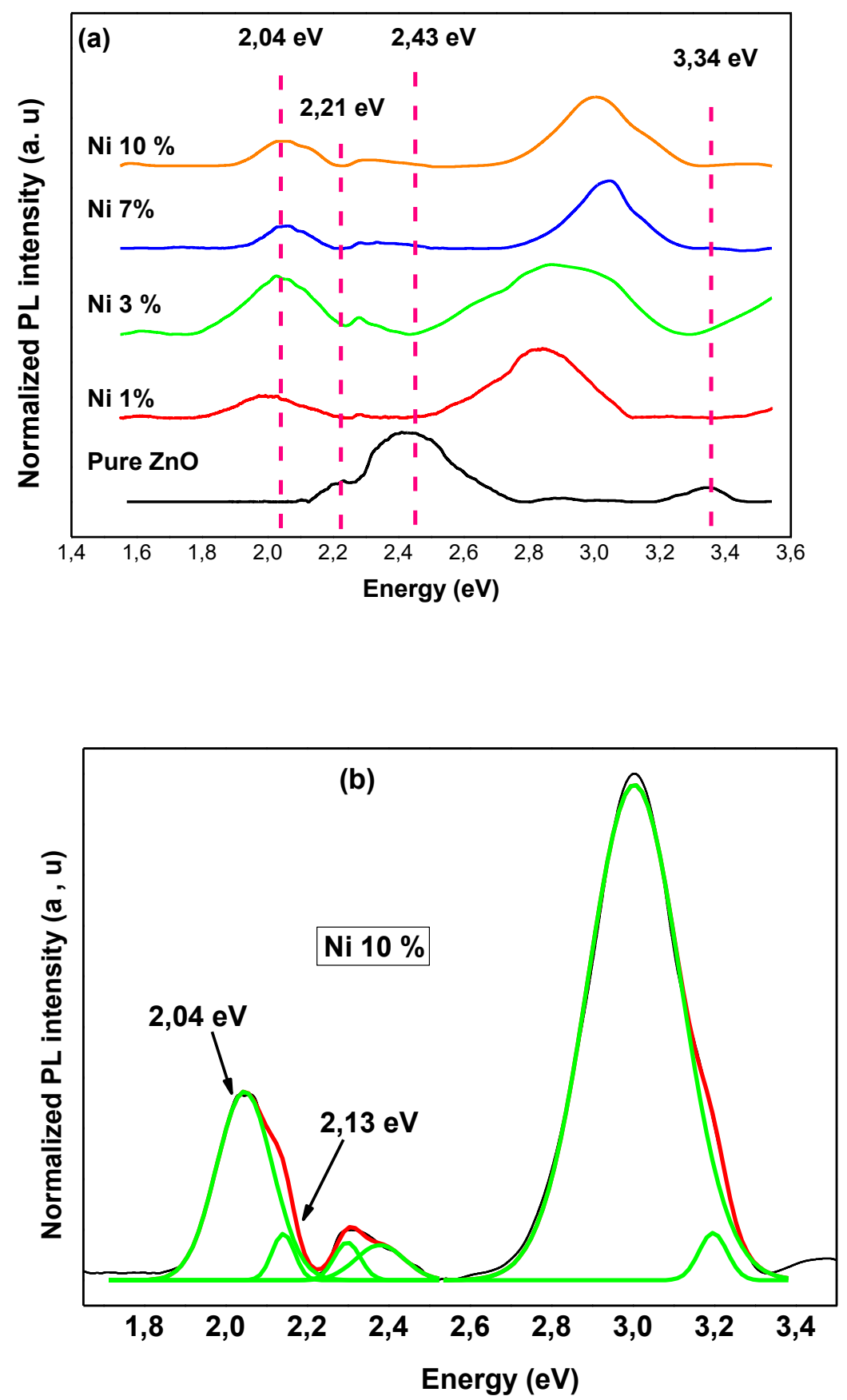

Figure 6. Cont. 


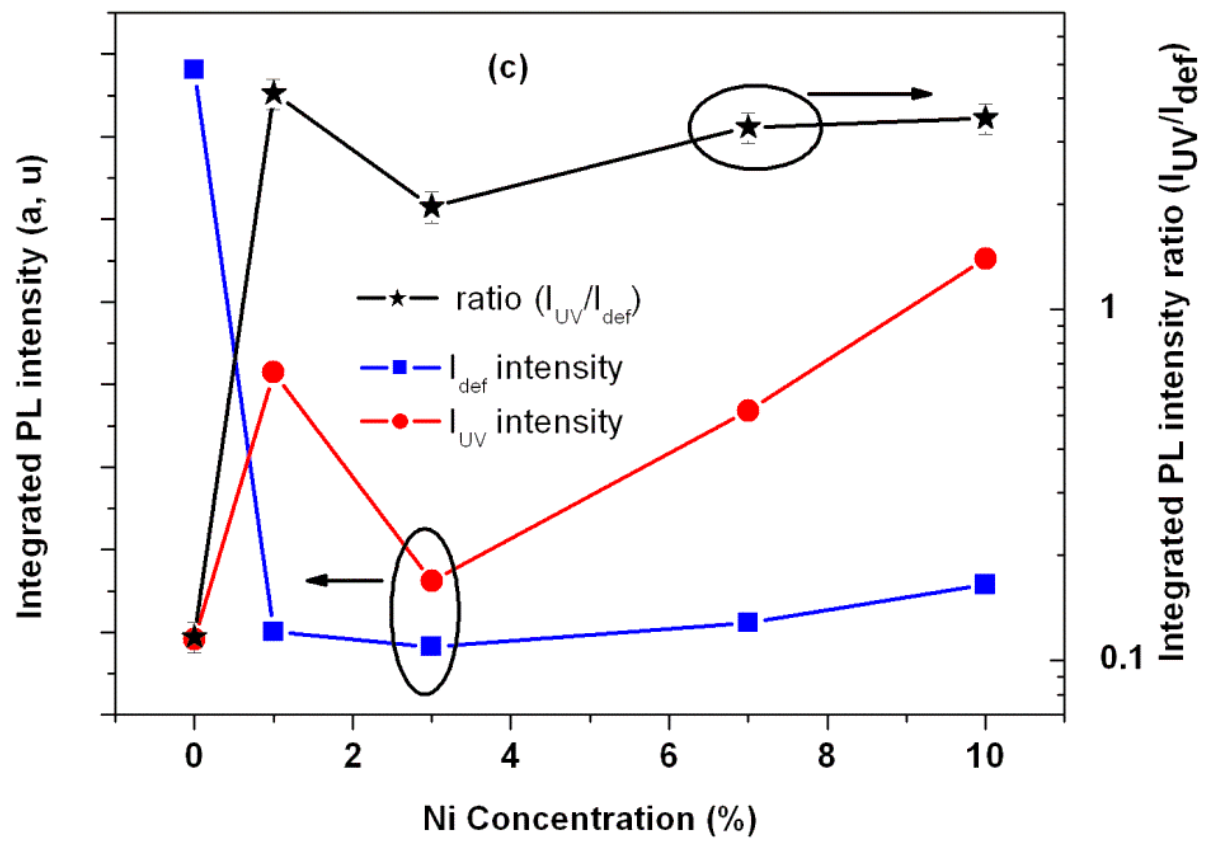

Figure 6. (a) Room temperature PL spectra of $\mathrm{ZnNiO}$ nanoparticles. (b) PL spectra of $10 \% \mathrm{ZnNiO}$ along with the Gaussian fit. Luminescence arising from the pure bulk $\mathrm{ZnO}$ is shown as a reference. (c) Integrated PL intensity of the UV band $\left(\mathrm{I}_{\mathrm{UV}}\right)$, the wide defect related band $\left(\mathrm{I}_{\mathrm{def}}\right)$ and relative PL peak intensities ratio $\mathrm{R}\left(\mathrm{I}_{\mathrm{UV}} / \mathrm{I}_{\mathrm{def}}\right)$ vs Ni concentration.

Raman analysis is very useful for finding $\mathrm{Ni}^{2+}$ doping-related changes in $\mathrm{ZnNiO}$ crystalline structure, such as the formation of structural disorders, presence of vacancies, or defects in host lattice [32,33]. The host $\mathrm{ZnO}$ has a wurtzite structure belonging to P63mc space group symmetry [54]. Eight active normal vibrational modes are present in the wurtzite $\mathrm{ZnO}$ comprising of two acoustic modes and six optical modes, of which four optical modes are Raman active [55]. Before explaining the Raman spectra of $\mathrm{ZnNiO}$, a brief description of expected vibrational modes is required. The major Raman modes of $\mathrm{ZnO}$, in Group theory's Mulliken notations, are $\mathrm{A}_{1}, 2 \mathrm{E}_{2}$ and $\mathrm{E}_{1}$. The $\mathrm{A}_{1}$ mode is symmetric to principal rotation axis (c-axis) and shows a mode split in the form of $A_{1}(T O)$ and $A_{1}(L O)$ modes relative to transverse and longitudinal one-dimensional atomic vibration. The split is due to the macroscopic electric field of LO vibration increasing the restoring force and stiffness of the bond, thus increasing the split $A_{1}$ mode's energy. Similarly, the two-dimensional $E_{1}$ mode is perpendicular to the c-axis, with displacements of the $\mathrm{O}$ - and $\mathrm{Zn}$ sub-lattices also showing polarity-induced stiffness and manifesting in the $\mathrm{E}_{1}$ mode's LO/TO splitting. However, the $\mathrm{E}_{2}$ mode is asymmetric on the c-axis and the polarity-induced macroscopic field can be easily cancelled out due to asymmetric motion of the sub-lattices. Hence, the LO/TO splits do not take place and the mode remains non-polar. Nevertheless, the $E_{2}$ mode further shows two components, low $\left(E_{2 L}\right)$ and high $\left(E_{2 H}\right)$ energy modes due to atomic mass difference between the $\mathrm{Zn}$ and $\mathrm{O}$ atoms. Additionally, some higher-order difference modes and surface phonon modes are also expected in wurtzite $\mathrm{ZnO}$. The usual Raman modes are often reported in the literature for the wurtzite phase of $\mathrm{ZnO}: \mathrm{E}_{2 \mathrm{~L}}-\mathrm{E}_{2 \mathrm{H}}, \mathrm{A}_{1}(\mathrm{TO}), \mathrm{E}_{2 \mathrm{H}}$, surface phonons and $\mathrm{A}_{1}(\mathrm{LO})[33,34]$. Raman spectra recorded for $\mathrm{ZnNiO}$ samples are shown in Figure 7 and all the usual Raman peaks are appropriately marked. The positions of the marked Raman peaks in $\mathrm{ZnNiO}$ are generally in agreement with the available literature [30,33,34]. The presence of all the expected Raman modes in the figure indicates conservation of wurtzite phase in $\mathrm{ZnNiO}$.

The highest intensity $\mathrm{E}_{2 \mathrm{H}}$ mode, related to two-dimensional doubly degenerate vibrations of $\mathrm{O}$-atoms, is very sensitive to internal stresses [34]. Ni doping has been reported to introduce new stresses and disorder in the cationic sub-lattice reducing the overall wurtzite symmetry of $\mathrm{ZnNiO}[30,33]$. $\mathrm{Ni}$ doping can also distort the local charge distributions in cationic sub-lattice leading to reduction 
in bond polarizability and reduced Raman intensity. $\mathrm{E}_{2 \mathrm{H}}$ mode intensity in $\mathrm{ZnNiO}$ is found to be reduced by $\approx 50 \%$ at $7 \%$ and $10 \% \mathrm{Ni}$ content in comparison to other compositions. The reduced Raman intensity indicates introduction of internal stresses in material as a result of doping. Both the Raman analysis and the XRD structural analysis point towards the presence of higher stress in $\mathrm{ZnNiO}$ samples. Moreover, doping-induced stress is also expected in $\mathrm{ZnNiO}$ samples because of the possibility of differences in dopants' radii of $\mathrm{Ni}^{2+}$ and $\mathrm{Ni}^{3+}$ ions [56].

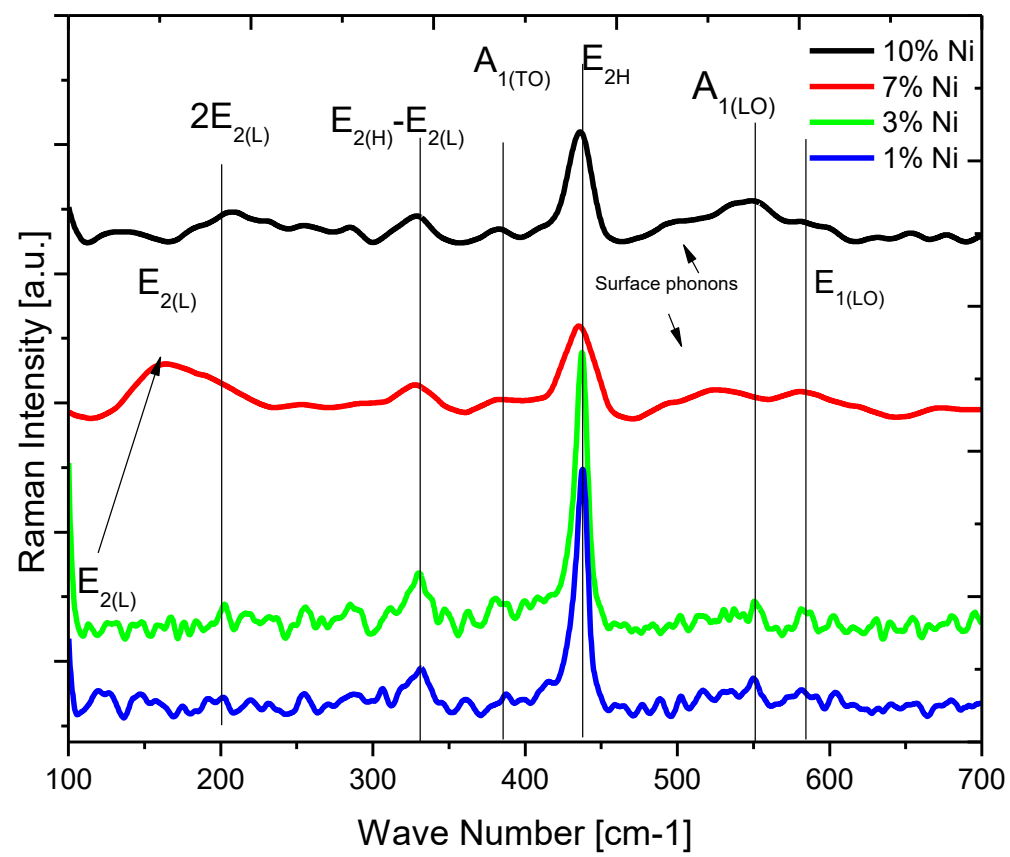

Figure 7. Room temperature micro Raman spectra for $\mathrm{ZnNiO}$ nanoparticles recorded in the confocal mode. Vertical lines show the positions of different normal modes of Raman vibrations. Ni content in the $\mathrm{ZnNiO}$ samples are written by $\mathrm{Ni}-1 \%,-3 \%,-7 \%$ and $-10 \%$, respectively, and the corresponding Raman spectra are plotted in blue, green, red and black colors.

The Raman modes, $\mathrm{A}_{1}(\mathrm{TO})$ and $\mathrm{A}_{1}(\mathrm{LO})$, are positioned at 380 and $550 \mathrm{~cm}^{-1}$, respectively, and according to the Lyddane-Sachs-Teller (LST) rule the mode positions indicate the ionic character of $\mathrm{ZnNiO}[34,57]$. The LST rule explains that the square of the ratio of LO and TO frequencies in the ionic lattice should be equal to ratio of static ( 8.5 for $\mathrm{ZnO}$ ) to optical (4.1 for $\mathrm{ZnO}$ ) dielectric constants. The $\mathrm{A}_{1}(\mathrm{TO})$ and $\mathrm{A}_{1}(\mathrm{LO})$ modes are also found to shift to higher frequencies with increasing Ni content in $\mathrm{ZnO}$ samples. The modes involve symmetric vibration of both $\mathrm{Zn}$ and $\mathrm{O}$ sub-lattices, and they are sensitive to the presence of $\mathrm{Ni}$ atoms in $\mathrm{Zn}$ sub-lattice. The ionic radii of $\mathrm{Ni}$ ions in octahedron coordination are $0.69 \AA, 0.56 \AA$, and $0.48 \AA$ for $\mathrm{Ni}^{2+}, \mathrm{Ni}^{3+}$ and $\mathrm{Ni}^{4+}$ ions, which are lower in size than $\mathrm{Zn}^{2+}, 0.74 \AA$. Low ionic radii cause a reduced distance in between the two sub-lattices and that increases the force constant of bond and vibration frequency. The intensity of $A_{1}(L O)$ mode was found to increase with $\mathrm{Ni}$ doping, which can be ascribed to the involvement of O-atoms only in the vibration, while the presence of vacancies can increase the mode intensity due to the change in bond polarizability.

The $\mathrm{E}_{2}$ overtone and difference modes arise at different positions due to higher-order $2 \mathrm{E}_{2 \mathrm{~L}}$ and difference $\mathrm{E}_{2 \mathrm{H}}-\mathrm{E}_{2 \mathrm{~L}}$ modes at peak positions $200 \mathrm{~cm}^{-1}$ and $330 \mathrm{~cm}^{-1}$, respectively. Disorder modes are also present in the nanoparticles, as is clear from Figure 7, at $530 \mathrm{~cm}^{-1}$, indicating the presence of either higher surface disorder, defect density or non-uniform strain, especially at $7 \%$ and $10 \%$ Ni doping percentages. The disorder modes have often been described as originating from the doping related structural defects and that results in manifestation of several broader line width phonons in doped $\mathrm{ZnO}$ [34]. 
XPS spectra for $\mathrm{Ni}_{2 p}, \mathrm{O}_{1 \mathrm{~s}}$ and $\mathrm{Zn}_{2 p}$ photoelectron binding energies (BE) in $\mathrm{ZnNiO}$ nanoparticles are shown in Figures 8-10, respectively, for assorted $\mathrm{Ni}$ doping concentrations. The $\mathrm{Ni}_{2 p}$ spectrum shows a general feature of two distinct XPS peaks at $\mathrm{BE}$ values of $854.3 \mathrm{eV}$ and $873.3 \mathrm{eV}$ for $\mathrm{Ni}^{2+}$ oxidation state and correspondingly related to $3 / 2$ and $1 / 2$ spin-split components of $\mathrm{Ni}_{2 p}$ electrons. Excluding the $\mathrm{ZnNiO}$ with $1 \%$ doping level, the $\mathrm{Ni}_{2 p}$ XPS peaks, as shown in Figure 8, exhibit a general feature of blue shifted binding energy and XPS peak broadening. Typically, the BE shift increases with doping of $\mathrm{ZnNiO}$, and the $\mathrm{BE}$ energy is blue shifted to $856.1 \mathrm{eV}$ at the $10 \% \mathrm{Ni}$ doping level, indicating the presence of both $\mathrm{Ni}^{2+}$ and $\mathrm{Ni}^{3+}$ oxidation states. A difference of $\approx 2.7 \mathrm{eV}$ has been reported previously in between the $\mathrm{Ni}^{2+}$ and $\mathrm{Ni}^{3+}$ oxidation states [58]. The $\mathrm{Ni}_{2 \mathrm{p}}$ BE blue shift $(-1.8 \mathrm{eV})$ indicates the presence of the additional $\mathrm{Ni}^{3+}$ oxidation state. Thus, the $\mathrm{Ni}_{2 \mathrm{p}}$ XPS results directly point towards substitution of multivalent $\mathrm{Ni}$ dopants, both $\mathrm{Ni}^{2+}$ as well as $\mathrm{Ni}^{3+}$, in $\mathrm{ZnNiO}$ nanoparticles, especially in the $\mathrm{ZnNiO}-10$ sample. Conversely, in the $1 \%$ Ni doped sample, $\mathrm{ZnNiO}-1$, should only have the divalent Ni doping because of the absence of the BE shift. The aforementioned Burstein-Moss blue shifts can also be easily explained by using the observation of $\mathrm{Ni}^{3+}$ oxidation states in the $\mathrm{ZnNiO}-10$ sample; the $\mathrm{Ni}$ atom is indeed behaving as a donor atom in $\mathrm{ZnNiO}$ nanoparticles at higher doping percentages $\geq 7 \%$.
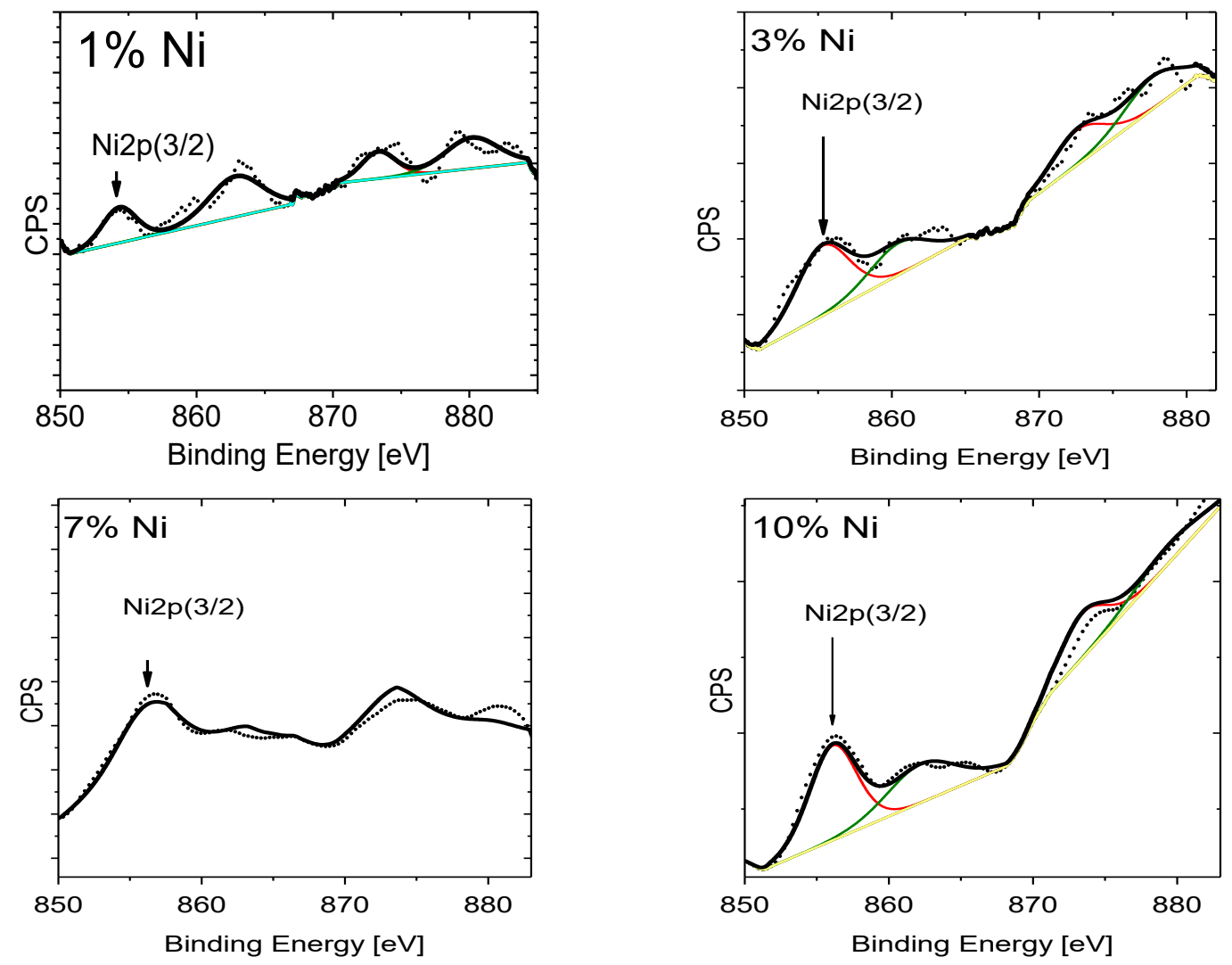

Figure 8. High-resolution XPS spectra are plotted for the $\mathrm{Ni}_{2 p}$ photoelectrons. XPS is recorded for the $\mathrm{ZnNiO}$ samples containing $1 \%, 3 \%, 7 \%$ and $10 \%$ Ni weight percentages.

A deconvolution of the XPS peak of $\mathrm{O}_{1 \mathrm{~s}}$ electrons in $\mathrm{ZnNiO}$ nanoparticles shows two peaks; the first peak is indicative of the native oxygen, and the second deconvoluted peak positioned at $532.5 \mathrm{eV}$ is related to the oxygen defects [58]. Indeed, the oxygen defects are found to increase at higher $\mathrm{Ni}$ doping, since the second $\mathrm{O}_{1 \mathrm{~s}}$ peak, as shown in Figure 9, becomes larger in area with doping, and that is also indicative of the formation of more oxygen defects due to $\mathrm{Ni}^{3+}$ substitution in the $\mathrm{Zn}^{2+}$ cationic sub-lattice. At higher Ni doping, the XPS spectra of the $\mathrm{Zn}_{2 \mathrm{p}}$ binding energy, see Figure 10, 
show relatively little change in the positions $1023 \mathrm{eV}$ and $1046 \mathrm{eV}$ of both types of $2 \mathrm{p}$ electrons of $\mathrm{Zn}$ ion. The $\mathrm{Zn}^{2+}$ oxidation state remains invariant to the doping.
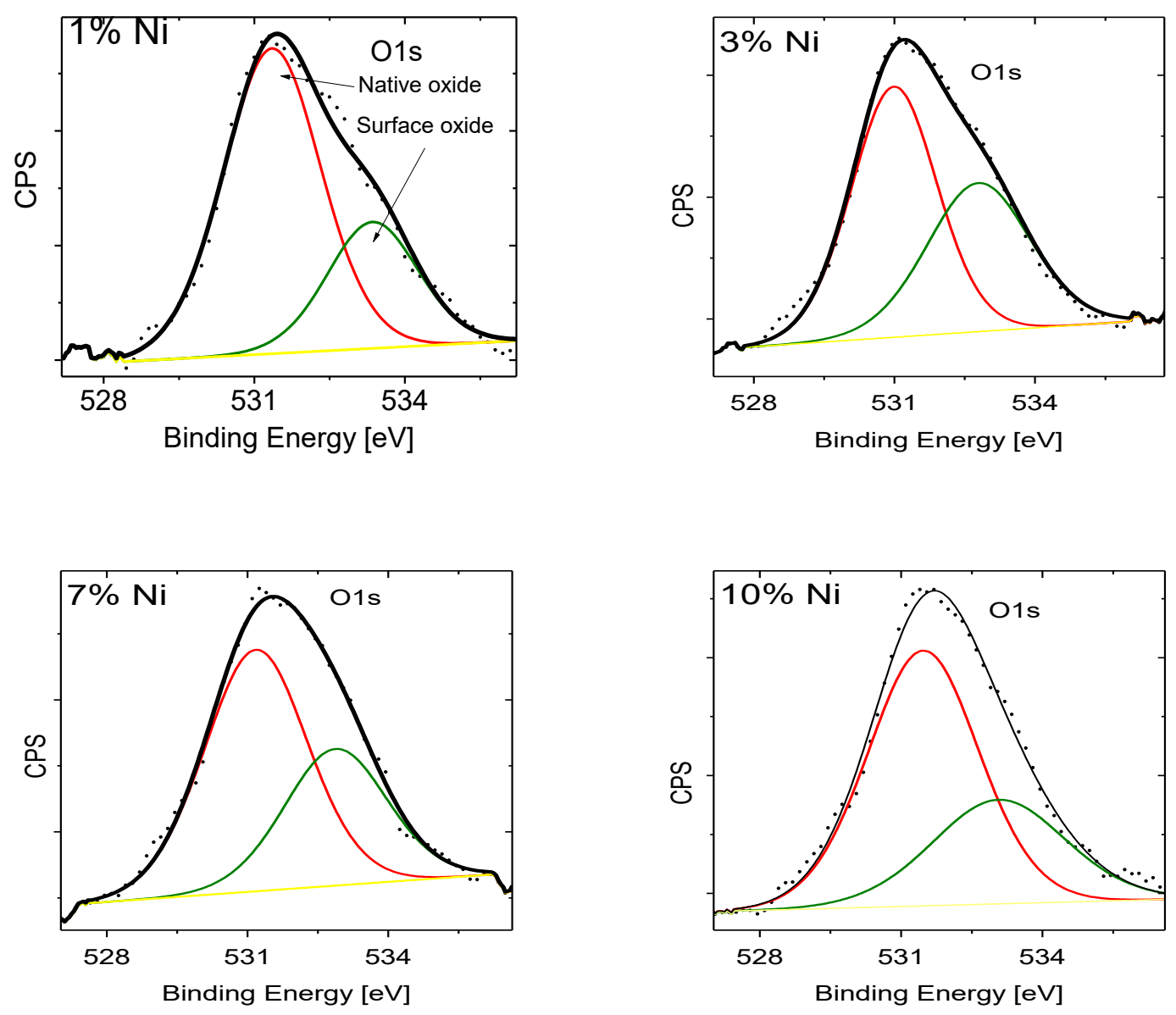

Figure 9. XPS recorded for the $\mathrm{ZnNiO}$ samples containing $1 \%, 3 \%, 7 \%$ and $10 \% \mathrm{Ni}$ weight percentages. High-resolution XPS spectra are plotted for the $\mathrm{O}_{1 \mathrm{~s}}$ photoelectrons.
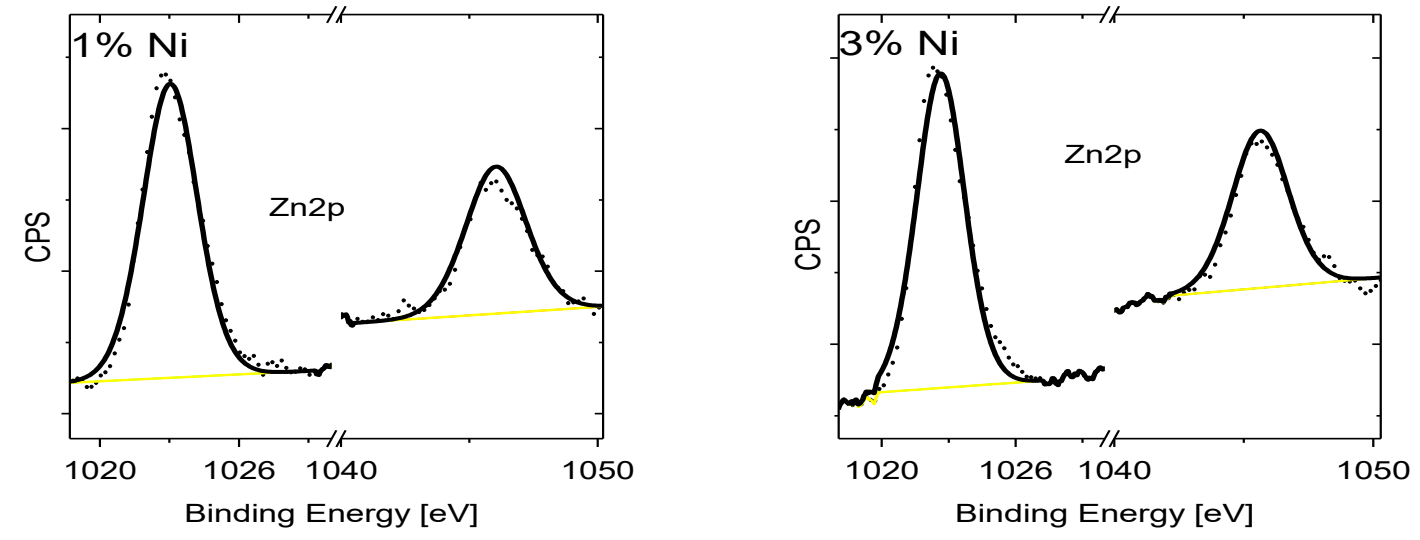

Figure 10. Cont. 

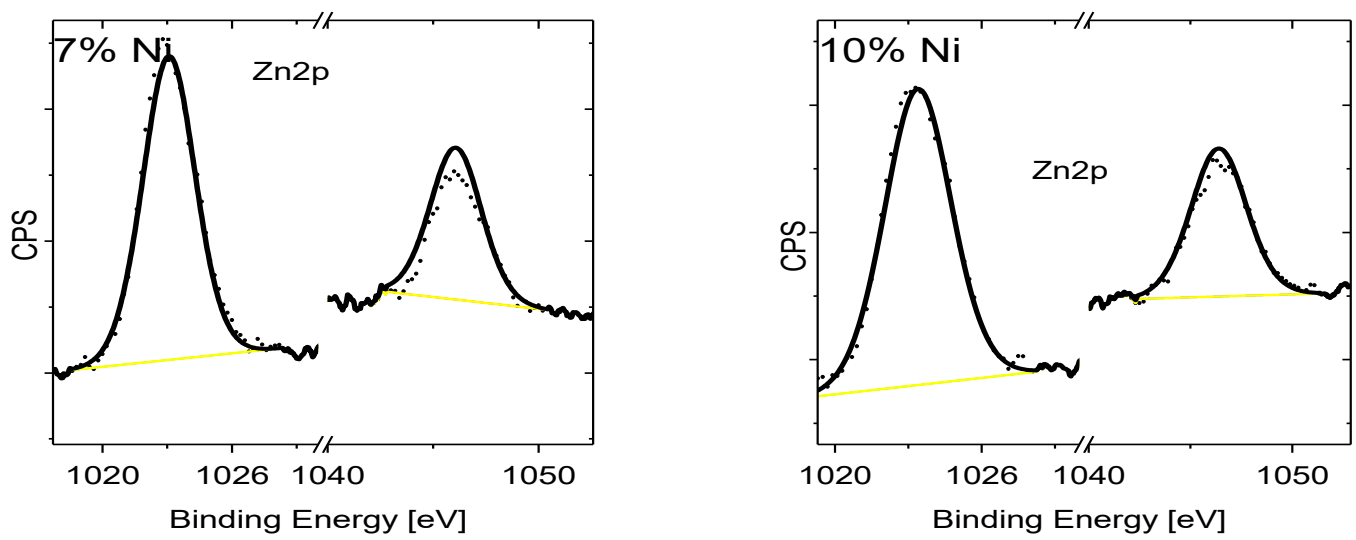

Figure 10. XPS recorded for the $\mathrm{ZnNiO}$ samples containing $1 \%, 3 \%, 7 \%$ and $10 \%$ Ni weight percentages. High-resolution XPS spectra are plotted for the $\mathrm{Zn}_{2 p}$ photoelectrons.

\section{Conclusions}

A simple sol-gel method is used to prepare $\mathrm{ZnNiO}$ nanoparticles at assorted doping levels by increasing the Ni concentration to $10 \%$. The dopant concentration was clearly found to significantly affect optical and structural properties of $\mathrm{ZnNiO}$ nanoparticles. XRD results indicate a substitutional solid solution phase among the ternary nanoparticles. No impurity phase is detected at all the assorted Ni doping percentages and all the observed XRD reflections can only be ascribed to wurtzite structural phase of $\mathrm{ZnNiO}$. However, reduced structural symmetry, crystal strain and structural defects are detected during the $\mathrm{XRD}$ analysis of $\mathrm{ZnNiO}$ nanoparticles. XRD peak-shifting and -splitting become clear at higher $\mathrm{Ni}$ doping levels $>7 \%$ and are attributed to the presence of crystal strain. Furthermore, the doping related decrease in Scherrer's particle size from $32 \mathrm{~nm}$ to $14 \mathrm{~nm}$ is also noted in $\mathrm{ZnNiO}$ nanoparticles. Spherical nanoparticle morphology is observed in SEM imaging with larger agglomerations of $\mathrm{ZnNiO}$ nanoparticles $(\approx 52 \mathrm{~nm})$ forming bigger clusters at higher doping. Kubelka-Munk function $\mathrm{F}(\mathrm{R})$ calculated from the DRS data is used to find the fundamental optical absorption onset. A small Burstein-Moss shift $\approx 0.1 \mathrm{eV}$ is observed in the linear-fit of KM function, which is credited to electrons transferred from the $\mathrm{Ni}$ dopant to the $\mathrm{ZnNiO}$ conduction band. Similarly, PL studies reveal intense UV luminescence in $\mathrm{ZnNiO}$ nanoparticles in comparison to pure $\mathrm{ZnO}$, and the UV PL emission peak is also found to be blue-shifted $\sim 0.15 \mathrm{eV}$ with $10 \% \mathrm{Ni}$ doping, further corroborating the Burstein-Moss effect. Raman analyses show a complete agreement with XRD structural studies. Doping-induced reduction in the Raman peak intensity of E-mode indicates a gradual decay of wurtzite character of $\mathrm{ZnNiO}$ nanoparticles. Additionally, polar Raman modes exhibit $\mathrm{Ni}$ doping related increased bond stiffness indicating presence of crystal strain in $\mathrm{ZnNiO}$ nanoparticles. Several disorder Raman modes are also observed in $\mathrm{ZnNiO}$ nanoparticles, confirming the presence of structural defects. Lastly, XPS studies show the presence of both $\mathrm{Ni}^{2+}$ and $\mathrm{Ni}^{3+}$ oxidation states at higher Ni doping. In this report, we have unequivocally shown the importance of multivalent $\mathrm{Ni}$ dopant states in the observed optical and structural changes of $\mathrm{ZnNiO}$ nanoparticles.

Author Contributions: Conceptualization, A.F.A.N. and J.M.; Data curation, A.H.F. and M.H.H.A.; Formal analysis, A.H.F., O.N. and M.H.H.A.; Funding acquisition, A.F.A.N.; Investigation, A.F.A.N. and J.M.; Methodology, A.H.F. and J.M.; Project administration, A.F.A.N.; Resources, A.F.A.N.; Software, A.F.A.N.; Supervision, J.M.; Validation, M.A. and O.N.; Visualization, M.A. and O.N.; Writing - original draft, J.M.; Writing - review \& editing, J.M. All authors have read and agreed to the published version of the manuscript.

Funding: This research is funded by DSR, King Faisal University by grant number RGST-17122004 and the APC is funded by DSR-RGST-17122004.

Acknowledgments: The authors acknowledge the Deanship of Scientific Research at King Faisal University for the financial support received under the Research Group Support Track (Grant No. 17122004).

Conflicts of Interest: Herewith, the authors declare that there is no conflict of interests in this work. 


\section{References}

1. Anandan, S.; Muthukumaran, S. Microstructural, crystallographic and optical characterizations of Cu-doped $\mathrm{ZnO}$ nanoparticles co-doped with Ni. J. Mater. Sci. Mater. Electron. 2015, 26, 4298-4307. [CrossRef]

2. Baruah, J.M.; Narayan, J. Dilute magnetic semiconducting quantum dots: Smart materials for spintronics. Nonmagn. Magn. Quantum Dots 2018, 87-199. [CrossRef]

3. Li, J.; Haney, P.M. Optical spintronics in organic-inorganic perovskite photovoltaics. Phys. Rev. B 2016, 93, 155432. [CrossRef] [PubMed]

4. Lalieu, M.L.M.; Lavrijsen, R.; Koopmans, B. Integrating all-optical switching with spintronics. Nat. Commun. 2019, 10, 1-6. [CrossRef] [PubMed]

5. Gałązka, R.R.; Zawadzki, W. Magnetoreflection and magnetophotoluminescence in the dilute magnetic semiconductor Zn 1- x Mn x Te. Phys. Rev. B 2018, 97, 214435.

6. Pradhan, N.; Das Adhikari, S.; Nag, A.; Sarma, D.D. Luminescence, plasmonic, and magnetic properties of doped semiconductor nanocrystals. Angew. Chem. Int. Ed. Engl. 2017, 56, 7038-7054. [CrossRef]

7. Liu, S.; Chen, Y.J.; Cui, H.N.; Sun, S.N.; Wang, Z.H.; Wang, H.S. Native Defect Luminescence of Zinc Oxide Films and Its Potential Application as White Light Sources. Guang Pu Xue Yu Guang Pu Fen Xi 2016, 36, 1604-1614.

8. Tong, L.N.; Cheng, T.; Han, H.B.; Hu, J.L.; He, X.M.; Tong, Y.; Schneider, C.M. Photoluminescence studies on structural defects and room temperature ferromagnetism in $\mathrm{Ni}$ and $\mathrm{Ni}-\mathrm{H}$ doped $\mathrm{ZnO}$ nanoparticles. J. Appl. Phys. 2010, 108, 023906. [CrossRef]

9. Chen, S.H.; Chen, W.C.; Yu, C.F.; Lin, C.F.; Kao, P.C. Influence of gallium-doped zinc-oxide thickness on polymer light-emitting diode luminescence efficiency. Microsc. Res. Tech. 2013, 76, 783. [CrossRef]

10. Song, G.L. Luminescence characteristics of terbium-doped nanocrystalline zinc oxide. Guang Pu Xue Yu Guang Pu Fen Xi 2007, 27, 2409-2412.

11. Gautam, U.K.; Imura, M.; Rout, C.S.; Bando, Y.; Fang, X.; Dierre, B.; Sakharov, L.; Govindaraj, A.; Sekiguchi, T.; Golberg, D.; et al. Unipolar assembly of zinc oxide rods manifesting polarity-driven collective luminescence. Proc. Natl. Acad. Sci. USA 2010, 107, 13588-13592. [CrossRef] [PubMed]

12. Khan, R.; Fashu, S. Effect of annealing on Ni-doped $\mathrm{ZnO}$ nanoparticles synthesized by the co-precipitation method. J. Mater. Sci. Mater. Electron. 2017, 28, 10122-10130. [CrossRef]

13. Xu, K.; Liu, C.; Chen, R.; Fang, X.X.; Wu, X.L.; Liu, J. Structural and room temperature ferromagnetic properties of $\mathrm{Ni}$ doped $\mathrm{ZnO}$ nanoparticles via low-temperature hydrothermal method. Phys. B Condens. Matter. 2016, 502, 155-159. [CrossRef]

14. Mihalache, V.; Negrila, C.; Bercu, V.; Secu, M.; Vasile, E.; Stan, G. Effect of dilute doping and non-equilibrium synthesis on the structural, luminescent and magnetic properties of nanocrystalline Zn1-xNixO $(x=$ 0.0025-0.03). Mater. Res. Bull. 2019, 115, 37-48. [CrossRef]

15. Muller, S.; Zhou, M.; Li, Q.; Ronning, C. Intra-shell luminescence of transition-metal-implanted zinc oxide nanowires. Nanotechnology 2009, 20, 135704. [CrossRef]

16. Liu, Y.; Liu, H.; Chen, Z.; Kadasala, N.; Mao, C.; Wang, Y.; Zhang, Y.; Liu, H.; Liu, Y.; Yang, J.; et al. Effects of $\mathrm{Ni}$ concentration on structural, magnetic and optical properties of Ni-doped ZnO nanoparticles. J. Alloy. Compd. 2014, 604, 281-285. (In English) [CrossRef]

17. Chacko, L.; Shafeeq, K.M.; Anjana, R.; Jayaraj, M.K.; Aneesh, P.M. Room temperature ferromagnetism in Zn1- x Ni x O nanostructures synthesized by chemical precipitation method. Mater. Res. Express 2017, 4, 105905. [CrossRef]

18. Aydin, C.; El-sadek, M.S.A.; Zheng, K.B.; Yahia, I.S.; Yakuphanoglu, F. Synthesis, diffused reflectance and electrical properties of nanocrystalline Fe-doped $\mathrm{ZnO}$ via sol-gel calcination technique. Opt. Laser Technol. 2013, 48, 447-452. (In English) [CrossRef]

19. Fabbiyola, S.; Sailaja, V.; Kennedy, L.J.; Bououdina, M.; Vijaya, J.J. Optical and magnetic properties of Ni-doped ZnO nanoparticles. J. Alloy. Compd. 2017, 694, 522-531. (In English) [CrossRef]

20. Jlassi, M.; Sta, I.; Hajji, M.; Ezzaouia, H. Effect of nickel doping on physical properties of zinc oxide thin films prepared by the spray pyrolysis method. Appl. Surf. Sci. 2014, 301, 216-224. (In English) [CrossRef]

21. Reddy, I.N.; Reddy, C.V.; Shim, J.; Akkinepally, B.; Cho, M.; Yoo, K.; Kim, D. Excellent visible-light driven photocatalyst of (Al, Ni) co-doped ZnO structures for organic dye degradation. Catal. Today 2020, 340, 277-285. [CrossRef] 
22. Reddy, I.N.; Reddy, C.V.; Sreedhar, A.; Shim, J.; Cho, M.; Yoo, K.; Kim, D. Structural, optical, and bifunctional applications: Supercapacitor and photoelectrochemical water splitting of Ni-doped ZnO nanostructures. J. Electroanal. Chem. 2018, 828, 124-136. (In English) [CrossRef]

23. Rauwel, P.; Salumaa, M.; Aasna, A.; Galeckas, A.; Rauwel, E. A Review of the Synthesis and Photoluminescence Properties of Hybrid ZnO and Carbon Nanomaterials. J. Nanomater. 2016, 2016, 19. (In English) [CrossRef]

24. Verma, K.C.; Bhatia, R.; Kumar, S.; Kotnala, R.K. Vacancies driven magnetic ordering in ZnO nanoparticles due to low concentrated Co ions. Mater. Res. Express 2016, 3, 076103. (In English) [CrossRef]

25. Asokan, T.; Freer, R. Characterization of Spinel Particles in Zinc-Oxide Varistors. J. Mater. Sci. 1990, 25, 2447-2453. (In English) [CrossRef]

26. Wu, M.S.; Chang, H.W. Self-Assembly of NiO-Coated ZnO Nanorod Electrodes with Core-Shell Nanostructures as Anode Materials for Rechargeable Lithium-Ion Batteries. J. Phys. Chem. C 2013, 117, 2590-2599. (In English) [CrossRef]

27. Carnes, C.L.; Klabunde, K.J. The catalytic methanol synthesis over nanoparticle metal oxide catalysts. J. Mol. Catal. A Chem. 2003, 194, 227-236. (In English) [CrossRef]

28. Hou, S.; Zhang, G.; Zeng, W.; Zhu, J.; Gong, F.; Li, F.; Duan, H. Hierarchical Core-Shell Structure of ZnO Nanorod@NiO/MoO2 Composite Nanosheet Arrays for High-Performance Supercapacitors. ACS Appl. Mater. Interfaces 2014, 6, 13564-13570. (In English) [CrossRef]

29. Mohapatra, J.; Mishra, D.K.; Kamilla, S.K.; Medicherla, V.R.R.; Phase, D.M.; Berma, V.; Singh, S.K. Ni-doped ZnO: Studies on structural and magnetic properties. Phys. Status Solidi B Basic Solid State Phys. 2011, 248, 1352-1359. (In English) [CrossRef]

30. Saravanan, S.; Silambarasan, M.; Soga, T. Structural, morphological and optical studies of Ag-doped ZnO nanoparticles synthesized by simple solution combustion method. Jpn. J. Appl. Phys. 2014, 53, 11 RF01. (In English) [CrossRef]

31. Sharma, P.K.; Dutta, R.K.; Pandey, A.C. Effect of nickel doping concentration on structural and magnetic properties of ultrafine diluted magnetic semiconductor ZnO nanoparticles. J. Magn. Magn. Mater. 2009, 321, 3457-3461. [CrossRef]

32. Du, C.L.; Gu, Z.B.; Lu, M.H.; Wang, J.; Zhang, S.T.; Zhao, J.; Cheng, G.X.; Heng, H.; Chen, Y.F. Raman spectroscopy of (Mn, Co)-codoped ZnO films. J. Appl. Phys. 2006, 99, 123515. (In English) [CrossRef]

33. Wahab, H. Tuning the band gap, electronic polarizability and conduction mechanism of DyxZn1-xO nanostructures: The role of band tail states. Mater. Res. Express 2018, 6, 015034. [CrossRef]

34. Russo, V.; Ghidelli, M.; Gondoni, P.; Casari, C.S.; Bassi, A.L. Multi-wavelength Raman scattering of nanostructured Al-doped zinc oxide. J. Appl. Phys. 2014, 115, 073508. [CrossRef]

35. Dey, R.; Bhunia, R.; Hussain, S.; Chakraborty, B.R.; Bhar, R.; Pal, A.K. Structural and Optical Studies on Sol-gel Composites of Nickel-Doped Nanocrystalline Zinc Oxide/Polyvinylidene Fluoride. Polym. Plast. Technol. Eng. 2017, 56, 310-320. (In English) [CrossRef]

36. Dey, R.; Yadav, A.K.; Bhunia, R.; Jha, S.N.; Bhattacharyya, D.; Hussain, S.; Bhar, R.; Pal, A.K. Probing local structure of co doped polyvinylidene fluoride- $\mathrm{ZnO}$ thin films using $\mathrm{X}$-ray absorption spectroscopy. Spectrochim. Acta Part B At. Spectrosc. 2017, 131, 115-123. (In English) [CrossRef]

37. Biesinger, M.C.; Payne, B.P.; Grosvenor, A.P.; Lau, L.W.M.; Gerson, A.R.; Smart, R.S. Resolving surface chemical states in XPS analysis of first row transition metals, oxides and hydroxides: $\mathrm{Cr}, \mathrm{Mn}, \mathrm{Fe}, \mathrm{Co}$ and $\mathrm{Ni}$. Appl. Surf. Sci. 2011, 257, 2717-2730. (In English) [CrossRef]

38. Lv, J.; Xu, J.; Zhao, M.; Sun, Y.; Jiang, Y.; He, G.; Zhang, M.; Sun, Z. Microstructure, surface morphology and optical properties of Na x Cu y Zn 1-x-y O thin films. J. Mater. Sci. Mater. Electron. 2016, 27, 4019-4025. [CrossRef]

39. Awan, S.U.; Hasanain, S.K.; Mehmood, Z.; Anjum, D.H.; Shah, S.A.; Aftab, M.; Abbas, T.A. Study of room temperature Raman scattering and XPS, high temperature electrical and low temperature magnetic properties of Zn1-yLiyO (0.00 $\leq$ y $\leq$ 0.10) nanoparticles. Smart Mater. Struct. 2015, 24, 115025. [CrossRef]

40. Norton, D.P.; Heo, Y.W.; Ivill, M.P.; Ip, K.; Pearton, S.J.; Chisholm, M.F.; Steiner, T. ZnO: growth, doping \& processing. Mater. Today 2004, 7, 34-40.

41. Thota, S.; Dutta, T.; Kumar, J. On the Sol-Gel Synthesis and Thermal, Structural, and Magnetic Studies of Transition Metal (Ni, Co, Mn) Containing ZnO Powders. J. Phys. Condens. Matter. 2006, 18, 2473. [CrossRef]

42. Lafuente, B.; Downs, R.T.; Yang, H.; Stone, N. The power of databases: The RRUFF project. In Highlights in Mineralogical Crystallography; De Gruyter: Berlin, Germany, 2015; pp. 1-30. 
43. Mazher, J.; Shrivastav, A.K.; Nandedkar, R.V.; Pandey, R.K. Strained ZnSe nanostructures investigated by $\mathrm{x}$-ray diffraction, atomic force microscopy, transmission electron microscopy and optical absorption and luminescence spectroscopy. Nanotechnology 2004, 15, 572-580. (In English) [CrossRef]

44. Chen, J.L.; Devi, N.; Li, N.; Fu, D.J.; Ke, X.W. Synthesis of Pr-doped ZnO nanoparticles: Their structural, optical, and photocatalytic properties. Chin. Phys. B 2018, 27, 086102. (In English) [CrossRef]

45. Weast, R.C. CRC Handbook of Chemistry and Physics; CRC Press: Boca Raton, FL, USA, 1988.

46. Jenkins, F.A.; White, H.E. Fundamentals of optics. Am. J. Phys. 1958, 26, 272. [CrossRef]

47. Lopez, R.; Gomez, R. Band-gap energy estimation from diffuse reflectance measurements on sol-gel and commercial TiO 2: A comparative study. J. Sol-Gel. Sci. Technol. 2012, 61, 1-7. [CrossRef]

48. Thien, N.D.; Tu, N.N.; Viet, N.N.; Phuong, N.D.; Long, N.N. Hydrothermal Synthesis and Optical Properties of Undoped and $\mathrm{Eu}^{3+}$-doped Zinc Stannate Nanocrystals. Commun. Phys. 2015, 25, 327. [CrossRef]

49. Nowak, M.; Kauch, B.; Szperlich, P. Determination of energy band gap of nanocrystalline SbSI using diffuse reflectance spectroscopy. Rev. Sci. Instrum. 2009, 80, 046107. (In English) [CrossRef]

50. Awan, S.U.; Hasanain, S.; Jaffari, G.H.; Anjum, D.H.; Qurashi, U.S. Defects induced luminescence and tuning of bandgap energy narrowing in $\mathrm{ZnO}$ nanoparticles doped with Li ions. J. Appl. Phys. 2014, 116, 083510. [CrossRef]

51. Srinet, G.; Kumar, R.; Sajal, V. Structural, optical, vibrational, and magnetic properties of sol-gel derived Ni doped ZnO nanoparticles. J. Appl. Phys. 2013, 114, 033912. [CrossRef]

52. Rajeh, S.; Barhoumi, A.; Mhamdi, A.; Leroy, G.; Duponchel, B.; Amlouk, M.; Guermazi, S. Structural, morphological, optical and opto-thermal properties of Ni-doped $\mathrm{ZnO}$ thin films using spray pyrolysis chemical technique. Bull. Mater. Sci. 2016, 39, 177-186. [CrossRef]

53. Rana, A.K.; Kumar, Y.; S, A.M.; Adarsh, K.; Sen, S.; Shirage, P.M. Enhancement of two photon absorption with Ni doping in the dilute magnetic semiconductor ZnO crystalline nanorods. Appl. Phys. Lett. 2015, 107, 231907. [CrossRef]

54. Downs, R.T.; Hall-Wallace, M. The American mineralogist crystal structure database. Am. Mineral. 2003, 88, 247-250.

55. Kroumova, E.; Aroyo, M.I.; Perez-Mato, J.M.; Kirov, A.; Capillas, C.; Ivantchev, S.; Wondratschek, H. Bilbao crystallographic server: Useful databases and tools for phase-transition studies. Phase Transit. 2003, 76, 155-170. (In English) [CrossRef]

56. Perry, N.H.; Bishop, S.R.; Tuller, H.L. Tailoring chemical expansion by controlling charge localization: In situ X-ray diffraction and dilatometric study of $(\mathrm{La}, \mathrm{Sr})(\mathrm{Ga}, \mathrm{Ni}) \mathrm{O} 3-\delta$ perovskite. J. Mater. Chem. A 2014, 2 , 18906-18916. [CrossRef]

57. Lyddane, R.H.; Sachs, R.G.; Teller, E. On the polar vibrations of alkali halides. Phys. Rev. 1941, 59, 673. [CrossRef]

58. Lu, Q.H.; Huang, R.; Wang, L.S.; Wu, Z.G.; Li, C.; Luo, Q.; Zuo, S.Y.; Li, J.; Peng, D.L.; Han, G.L.; et al. Thermal annealing and magnetic anisotropy of NiFe thin films on $\mathrm{n}(+)$-Si for spintronic device applications. J. Magn. Magn. Mater. 2015, 394, 253-259. (In English) [CrossRef] 